\title{
Distance Gradient in Prenatal Dental Development
}

\author{
STANLEY M. GARN, ALPHONSE R. BURDI, and JERROLD M. NAGY \\ Center for Human Growth and Development and Department of Anatomy, The University \\ of Michigan, Ann Arbor, Michigan 48104, USA
}

In postnatal dental development, and in crown size itself, there is a demonstrable "distance gradient" so that teeth closer together within a jaw quadrant show higher correlations. Thus, adjacent teeth exhibit systematically higher communality in both tooth formation and crown size than more remote teeth in the same quadrant, despite absolute differences in formation (calcification, root elongation, and movement) and in crown size (specifically the mesiodistal crown diameter) (S. M. GARN, A. B. LEWIS, and R. S. KerewsKy, J Dent Res 44: 350-354, 1965 and 46:1481, 1967; S. M. GARN, C. G. Rohmann, T. Blumenthal, and F. N. Silverman, Amer J Phys Anthrop 27:75-82, 1967).

We applied this analytic model to intraindividual correlations of tooth stage in the $20 \mathrm{de}$ ciduous teeth of 52 male and female embryos in the 14 to $58 \mathrm{~mm}$ size range; all embryos were macroscopically and histologically "normal" (A. R. BURDI, S. M. GARN, and R. L. Miller, J Dent Res 49:889, 1970.) By first separating the correlations according to sex, and then combining them and pooling correla-

This study was supported, in part, by University of Michigan Faculty Research Grant Project 21 and University of Michigan computational services for academic staff research.

Additional information available on request to authers. Received for publication November 30, 1970. tions according to degree of proximity, the hypothesis of a distance gradient was confirmed.

As indicated in the table, adjacent teeth showed the highest developmental correlation, teeth separated by one intermediate tooth showed lower mutual correlations, teeth separated by two teeth showed still lower correlations, and deciduous teeth separated by three intervening teeth showed the lowest correlations. This "distance gradient" was true for maxillary and mandibular teeth, and for both male and female embryos although intraembryo correlations were systematically higher for female embryos. Overall, the values of $r$ dropped by 0.04 for each intervening tooth. Adjacent teeth of the same morphologic class (deciduous incisors or deciduous molars) were only slightly higher in developmental communality than adjacent teeth of different morphologic classes (eg, deciduous canine and deciduous first molar).

This preliminary analysis, restricted to the 14 to $58 \mathrm{~mm}$ embryo, confirms the applicability of analytic models borrowed from postnatal dental development, and indicates that anatomic "distance" is a useful structuring principle in both prenatal and postnatal developmental time. Closer developmental communality between teeth of a single morphologic class appears to be, for the most part, a product of minimal distance.

TABLE

Distance Gradient in Prenatal Dental Development

\begin{tabular}{|c|c|c|c|c|c|c|}
\hline \multirow{3}{*}{$\begin{array}{l}\text { Type of } \\
\text { Correlation }\end{array}$} & \multirow{3}{*}{$\begin{array}{c}\text { No. of } \\
\text { Intervening } \\
\text { Teeth }\end{array}$} & \multicolumn{5}{|c|}{ Intraquadrant Developmental Correlations } \\
\hline & & \multicolumn{2}{|c|}{ Males } & \multicolumn{2}{|c|}{ Females } & \multirow{2}{*}{$\begin{array}{c}\text { Combined } \\
r\end{array}$} \\
\hline & & $r_{s}$ & $r$ & $r_{s}$ & $r$ & \\
\hline \multicolumn{7}{|c|}{ Maxilla } \\
\hline Intraquadrant & 0 & 4 & 0.903 & 4 & 0.952 & 0.932 \\
\hline Intraquadrant & 1 & 3 & 0.834 & 3 & 0.919 & 0.883 \\
\hline Intraquadrant & 2 & 2 & 0.735 & 2 & 0.901 & 0.837 \\
\hline Intraquadrant & 3 & 1 & 0.740 & 1 & 0.883 & 0.824 \\
\hline \multicolumn{7}{|c|}{ Mandible } \\
\hline Intraquadrant & 0 & 4 & 0.917 & 4 & 0.943 & 0.931 \\
\hline Intraquadrant & 1 & 3 & 0.831 & 3 & 0.887 & 0.862 \\
\hline Intraquadrant & 2 & 2 & 0.774 & 2 & 0.831 & 0.804 \\
\hline Intraquadrant & 3 & 1 & 0.701 & 1 & 0.862 & 0.795 \\
\hline Intraclass adjacent & 0 & 4 & 0.923 & 4 & 0.954 & 0.941 \\
\hline Interclass adjacent & 0 & 4 & 0.896 & 4 & 0.938 & 0.919 \\
\hline
\end{tabular}

All values of $r$ are derived from mean $z$ transformations of $r$, and are based on the number of correlations shown. 